\title{
Anomie and Order Return of the Family Support Tradition for the Elderly in Rural China
}

\author{
Facheng Gao \\ Department of Sociology of the Faculty of Law and Politics \& Administration \\ Guangdong Ocean University \\ Zhanjiang, China
}

\begin{abstract}
Traditional order of elderly support in rural China focuses on filial piety and support, with family support as the main form and manifestation of offspring's filial piety and support to their parents, which is called as family support for the elderly. However, nowadays, rural elderly support encounters the dilemma of separation of filial piety and support because of population flow and focus shift-down of intergenerational relationship caused by economic development. Meanwhile, the social and economic status of the aged has been weakened, which makes family support for the elderly increasingly tensional. Therefore, rural elderly support is eager to escape from control of traditional order. The only way that we can guarantee the later life of the rural elderly is to return to the root of family support for the elderly. We must build a perfect system of elderly support with health care for the elderly as a point of breakthrough, in order to let individual, family, community and state return to order ultimately.
\end{abstract}

Keywords-Social order; Chinese native soil society; family support for the elderly; anomie; order return

\section{INTRODUCTION}

China will be an irreversible aging society in the 21st century. The media calls the problems of health care, education, elderly support and housing of urban residents as the new "four mountains". Today, the phenomenon of "abandonment" of rural elderly has been constantly reported. The construction of the elderly support system in rural China which features "based on family support, supported by community service and supplemented by institutional care" has encountered unprecedented difficulties, which fully shows that we should re-examine our research path and return to the most fundamental land in rural areas to understand the most authentic issues in rural China. The tradition of filial piety and support in rural China is, under certain social order, to comply with reciprocity emphasizing on monophyletic lopsidedness and internalized notion of having sons for elderly support, which forms an order of family support for the elderly: parents and their offspring are the main part of the order, including parents' upbringing of their offspring and offspring's support to their parents. The parent-child relationship on the basis of consanguinity featuring parents' upbringing of their offspring changes, after

This article was supported by "2013 University-Level Humanities and Social Sciences Research of Guangdong Ocean University" (No. C14050), awarded by Guangdong Ocean University. their offspring enter adulthood, to the filial piety and support relationship featuring offspring's support to their aging parents, which is the feedback model of intergenerational reciprocity and becomes a subject behavior established over the parent-child relationship and morality and ethics.

\section{FAMILY SUPPORT FOR THE ELDERLY IN CHINESE Rural Areas Become A Big Problem in Times of Socio- ECONOMIC DEVELOPMENT}

"Young offspring will be brought up by their parents; offspring will take care of their aged parents till dying a natural death. It is a mutual treatment as to two generations, " (Pan Gongdan, 1994), which is an ethic concept naturally adopted by members of society as a general social fact constituted through thousands of years of development of the production and living organization forms selected by traditional agricultural society, which contributes to the formation of the culture of filial piety in kinship organizations with family as a unit and extension to all sectors of society. This culture of filial piety reflects the matching with the production mode of Chinese traditional agricultural society, ensures the transfer and expansion of production capacity, and thus builds the order of filial piety and support of family members regarding ethics and morals, that is, the elderly support mode in rural China based on family support for the elderly. It "takes family unit as the core, consanguinity, kinship and other social relations as links, and traditional culture of filial piety and respect for elders as support, which support and connect with each other" (Su Baozhong, 2009). The culture of filial piety and family support for the elderly thus constitutes the behavioral mechanism to run the elderly support order of traditional Chinese society. Researchers (Cao Liqian, Gao Shanxiu, 2008) believe that although the culture of filial piety to a certain extent features obscurantism, inequality, feudalism and conservatism, the spirit of filial piety should inherit and develop. For family life, family relations, regulation of relations between juniors and seniors, the culture of filial piety has significance for practice and reference of its existence. However, Chinese tradition encountered unprecedented challenges from the perspective of the reality of today's society. An aging population brings increasingly heavy burden for family support for the elderly and, at the same time, more and more young adults flow into cities, which causes a result that both daily care and economic 
support for old people become problems. At the same time, the health problems of the elderly have become a new economic problem seriously concerned by aging countries, since health insurance support and costs for public health care services for the elderly are huge overhead to the state finances. Foreign scholars thus mainly concentrate on elderly support welfare in terms of rural elderly support, particularly concerning family support for the elderly, economic support and living conditions, etc., in order to restore the true aging problems in such ancient country. Rita Jing-ann Chou (Rita Jing-ann Chou, 2010) used the theory of integration and logistic regression analysis method, according to survey data from 20,255 elders in China, and compared data and conclusions in Chinese literature regarding analysis on acceptance of China's elderly population on social elderly support. She reached a conclusion that China's rural and urban elderly population, in the choice of whether to accept the social elderly support services, were affected by factors including gender, status of family harmony, filial piety of offspring, socio-cultural beliefs and practices regarding children upbringing and elderly support, understanding and perception of social elderly support institutions, as well as self-evaluation on economic status. Meanwhile, she believed that other factors had different influence on affecting rural and urban elderly population to select social elderly support services. Especially, With respect to sex factor, urban elderly women were more willing to select social elderly support services, but the will of rural elderly women were opposite. At the same time, the rural elderly population having the notion of "having sons for elderly support" had lower willingness of accepting social elderly support. Deborah Sue Wilson Lowry (Deborah Sue Wilson Lowry , 2008), when working on her doctoral dissertation, spent six-month time in field work in a village called "Seven Mountains" in Fujian, China to explore in depth the experiences, views and expectations of the elders in the village on relationship between China's population aging and China's economic and social change. She focused on discussing how changes and economic development in rural China shaped the life of rural elderly, and in turn, how they affect such changes and development; also, what kind of later life the rural people who are about to join the ranks of elderly look forward to. Based on her fieldwork, Lowry believed that there is a difference between Chinese scholars' macro understanding of rural elderly and self-awareness of the rural elderly, the reason of which was that how to interpret the demographic phenomenon depended on their own social status. The example of "Seven Mountains" manifested that economic development could not guarantee a happy life of the elderly.

The elderly who are unable to accept social support and also cannot obtain enough support resources for their later life often have to continue to work to support grandchildren who also stay in rural areas. "Economic self-sufficiency is currently the most important source of support for the rural elderly in less developed areas. Although family support still plays an important role, it takes second place. The level of protection regarding institutional economic support on the elderly in rural areas is still relatively low"(Chen Fang, 2014). The way for rural population to pursue wealth in modern development exerts a significant impact on the tradition of rural family support for the elderly in three aspects:

First, the new-generation migrant workers live urban life and are unable to extricate themselves from excessive consumption. As a result, they are unable to reversely feed their family, let alone show solicitude for the later life of the elderly. Comparing with the survival skills and manners with their parents, the new-generation migrant workers in urban areas achieve rapid development and progress. However, due to lack of innate competitiveness, unhealthy ways and customs and heavy survival pressure in urban areas, most of the new-generation migrant workers easily fall into excessive consumption in cities to exchange enjoyment beyond their ability to defray. With deeper implantation of urban culture, the relation between new-generation migrant workers and their parents is becoming increasingly loose. There is almost no emotional exchange. Elderly support has undoubtedly become the victim in the development of population movements.

Second, empty nest of rural families becomes increasingly serious. The economic status of the rural elderly continues to decline, and ethics therefore no longer plays a part in constraining refusal of support for the elderly. Following the deepening of economic development, the flow of young labor force continues to accelerate with scope expansion. The elderly soon find out their offspring divorced from binding of land not only rarely take care of the family, but also quietly change the resource allocation way centered in the elderly. The authority of the elderly in traditional agricultural society gradually ceases to exist. The elderly are placed under the bottom of modern life. At the same time, outputs from the physical power of the elderly and outputs from land become greatly reduced. On the contrary, income sent by migrant offspring has become important support for rural family life. However, even with regular remittance of living expenses, it is more and more common to have only the elderly and children in rural households. Young adults may not return home all year round, and the living expenses are thus mainly used for the costs of living and study of grandchildren. Once offspring is unable to guarantee their material life, the case of shirking support for the elderly will easily occur, which can no longer be bound by ethics. However, kind-hearted peasants would exculpate their offspring with the understanding that they would not blame their offspring because the offspring's survival is not easy and old people are cumbersome.

Third, the economic base to support the culture of filial piety has been hard hit. Miniaturization of family structure and focus shift-down of intergenerational relationship cause the loss of the elderly's authority of the past. Land and power that could be exchanged with the offspring have lost their superiority under the background of population movement and pursuit of wealth. Even the status of grandchildren is better than the elderly. The economic capacity of the offspring, in modern development evolves the traditional elderly support mode in rural areas into sharp money consumption. At the same time, the "small farmer" idea of "for the next generation" lets the elderly support with economic supply by offspring becomes almost impossible. 
More and more researches show that rural areas will be the difficulties and focus of future elderly support problems in China.

\section{FAMILY ELDERLy SUPPORT IN THE CHINESE NATIVE SOIL SOCIETY: FAMILY, ETHICS, MONEY}

Social order "is the way to coalesce the community and is consistency, continuity and certainty of a certain degree existed in the functioning of society. In essence, the social order is institutionalization and normalization of relations between people. It is not only a process to practice a variety of social behavior norms of human, but also the result of practice. Order is the main indicator and basic value of a harmonious society. There is no harmony without order. The ought-to-be goal of social order is balance and harmony. The achievement of multi-effective supply of social order will also promote construction and generation of a harmonious society" (Song Siyun, 2010). Such concept defines a cognitive perspective easily neglected, that is, interaction of social subjects. Individual's pursuit of freedom must be limited to an unfree state. Whether such state is achieved through regulation of order or individuals' self-restraint is the key to cause confrontation of freedom and order. Social order does not exist for an individual, but requires necessary interaction of subjects. Only based on this sense it will restrict to individual freedom and generate confrontation. Thus, the social order is a state of balance and the stable and consistent results of interaction among subjects.

The Chinese native soil society is an accurate judgment given by Mr. Fei Xiaotong as to the traditional social structure of rural China. Such Chinese native soil society is a society of etiquette and customs structured with land as basis, village as a unit as well as acquaintances as the network. It is also the gathering place for people who rely on the land to survive. They are so familiar with the land that there is no barrier among them in the "rustic" environment. This "acquaintance" is a differential pattern like ripples of waves and featuring measurement or inferring of others from own perspectives. It is formed with consanguinity and geographical relationship as links and individuals as the center. Everyone in this structure is the center of the circle formed by his/her social influence. With respect to any other person affected by the ripples of the circle, they will have contact with each other, which is the "basic characteristic of the Chinese social structure". So, families based on parentchild relationship and clans derived with families as the core become the behavior basis of interactions among subjects in the Chinese native soil society. Commonly, Parents bring up their offspring and in return, the offspring in adulthood take care of their parents who are old and weak or are unable to work. Such intergenerational reciprocity containing "feeding" and "regurgitation-feeding" and featuring two-way communication and two-way balance based on the principle of equity becomes necessary constraint mechanism towards subjects with respect of filial piety and support. Therefore, what the traditional order of rural family support for the elderly refers is the intergenerational exchange relationship based on the Chinese native soil society and with parentchild relationship as the center. It is formed based on responsibilities and obligations assumed by the offspring towards the later life of their parents. It is also about the cultural tradition of filial piety and a standardizing system of support. This order cannot be simply attributed to the context of consanguinity and kinship. On the contrary, it has been widely affected by traditional concept and modern development and becomes a value idea issue within the context of culture.

There is a basic understanding in China's agricultural society with thousands of years. "The pursuit of order and avoidance of unrest is a prominent cultural orientation in China" ${ }^{1}$. In order to establish and maintain social order, Confucianism gradually combined with Legalism and the phenomenon of "Confucianism featuring Legalism" occurred. Thereupon, the combination of enlightenment means and coercive measures became two "magic weapons" to control China's social order. (Zhang Desheng, 2008) "Long-term education has turned external rules into internal habits" (Fei Xiaotong, 2005). The basic characteristic of the order of the Chinese native soil society is tradition and the order of the Chinese native soil society is sustained based on tradition. Therefore, the establishment and continuation of an elderly support order will not easily be interrupted by transformation or even revolution of society. It itself and the subjects and subject behaviors regulated by it confront the behavior mechanism towards disorder, manifesting its authority and value.

Why disorder of this elderly support order is difficult to be punished in modern society? When the cases of mistreatment and shirking of support for the elderly occur, the elderly rarely take legal action to protect their own rights and interests because of personal relations within the family and the litigation-avoided etiquette and customs of "don't wash one's dirty linen in public". In addition, with the rural custom of "officials will not investigate and affix liabilities without civilians' reporting of relevant crimes", more and more young people "follow" the example of shirking support for the elderly. Once they have so-called economic difficulties, they will cease to look after the elderly. They are not ashamed of shirking support for the elderly and do not take it as un-filial. Therefore, it is not difficult to try most of the cases that the elderly sue their offspring, but it is rather difficult to procure the offspring to perform their bounden obligation towards the elderly. The fundamental reason is that we blotted out the symbol of "support" and etiquette of "supporter and the person being supported" when dealing with the ritual system during cultural transformation period. "Based on the principle of exchange theory, the relationship between the caregiver and the person under care should be measured based on the capabilities that the parties can use to repay each other with some value. For example, the resources that can be used to reward others in the exchange relationship include private aid, household chores, money, information, feelings, favor, labor, obedience, or various material support. If the capabilities of either party to reward the other is weak in an exchange relation, then such party

\footnotetext{
${ }^{1}$ See Confucian Ethics, Sociology and Political Order of Jin Yaoji, which is the preface of Confucian Ethics and Order Complex (2008) of Zhang Desheng.
} 
would be considered a relying party" (Thomas J. Durant, Jr., Ollie G. Christian, 2006). It is clear that the elderly and children are the relying party in exchange in families. For rural people, their parents and their offspring do not have a reciprocal economic advantage in exchange. The "support" for them, that is, raising and elderly support, must give way to economic advantage. From another point of view, the boundary of "support" is blurred, that is, caregiver refers to the offspring undertaking elderly support and the elderly under care refers to the elderly needing support. Therefore, consistency that should exist on the boundary of "support" is no longer in existence. That means the caregiver's assumption of elderly support obligation and enjoyment of the elderly under care should happen consistently on the boundary of "support", which is like two coexisting sides of a coin. However, the boundary now is ill-defined, causing the loss of basis of existence of consistency. Accordingly, offspring will abandon support to the elderly in need of care with the reason of economic difficulty and will not be disciplined; when the offspring want the elderly to live an easy life in their old age, the elderly will claim that they still have productive capacity. The elderly will continue to contribute to the family economy without being forced into the later life under care.

Without boundary of "support", there are no mandatory rules for elderly support. Even "due to the general decline in patriarchal basis, in addition to family constraints, elderly support no longer has a strong system binding and guarantee, which, to a large extent, has become a system depending on personal willingness and intrinsic moral of the offspring" (Tang Can, Ma Chunhua, Shi jinqun, 2008). The tradition of family support for the elderly in rural China at this era of economic development is confused by money and eager to stay out of control of order, which is primarily a breakthrough of morality constraint.

\section{SEPARATION OF FILIAL PIETY AND SUPPORT: RURAL FAMILY SUPPORT FOR THE ELDERLY THAT IS EAGER TO STAY OUT OF ORDER}

General public commonly put the pursuit of economic efficiency in the first place in current society due to modernity development. Support and filial piety given by offspring for their parents have been gradually separated due to influence from various factors including economic capacity, social status and spatial distance. Today, life is getting better and better, and offspring is filial piety to their parents, which is generally not suspected. However, whether they will take care of their parents has become a problem. The manifestation of this relationship in rural areas is that the later life of the rural elderly becomes a greater problem due to mobility and changes in economic status caused by the migration of the offspring to other places to work. It also manifests prominently in the relationship between filial piety and support. With respect to filial piety, relationship by consanguinity between parents and offspring naturally endows the two generations with such social attributes that offspring should look after parents with filial piety and highlight the traditional virtues. Support is the most direct material state of filial piety including respect for parents, showing great concern for parents, serving tea and water, sending parents to receive medical care, looking after parents in bed meticulously, and taking good care of parents when they are living and giving them proper burial after death.

However, with the impact of the migration of the offspring to other places to work and focus shift-down of intergenerational relations, there is an absence of time guarantee and supervision of public opinion with regard to filial piety of offspring. Also, the obscure "when to support" lead to the circumstance that the offspring assuming elderly support and their parents under support cannot keep in step with each other. Consequently, filial piety nowadays loses balance and affects the stability of the order of elderly support. However, the order, with its own strength and the subject behavior mechanism of order, restricts subjects and subject behavior from heading to disorder and maintains the established order to continue to run.

Firstly, modern problems encountered regarding elderly support in rural China: traditional elderly support willingness and the reality of "difficult to receive elderly support even having sons", division of family property and "split" of elderly support, daughter married away from parents and daughter-in-law from other places, "abandonment of support to parents" due to mobility and left-behind elderly losing power and influence and suffering setbacks, growth of the total economy and shrinking of personal income. Secondly, the fact that fails to change - the traditional order of the Chinese native soil society: family formation, inheritance and replacement, property accumulation and distribution offspring's positioning and function, customs and functions of support when living and burial after death, as well as attribution after mobility. Finally. new expansionism of family support for the elderly: basis of rural China - maleroot monophyletic institutional arrangements, family for the elderly to die a natural death - strengthening moral constraints on family support for the elderly, economic development and cultural consciousness - national strategy for people to accumulate for the future, dependency of organizations and individuals - new features of China's rural collective economy.

Elderly support in poor rural households still rely mainly on the number of offspring. Mobility and migration geographically of rural labor further sharpen the matters regarding shortage of resources for elderly support and care emerged because of family planning and small family miniaturization. The impact of mobility mainly reflects on change of an important condition on which family support replies - close consanguinity. The primary impact is that it is unrealistic for rural elderly to receive life care and spiritual solace from offspring due to geographic separation. Although migrant workers are likely to improve the ability of economic and material support to the elderly, this is only a possibility. Some scholars have even found that rural intergenerational relations even showed that young people "exploited" parents when getting married and parents retained private savings for their own later life (He Xuefeng, 2009). Strengthening population mobility causes a result that once the parents nowadays become the elderly, especially lose the ability to work and start to need caring from offspring, they find no offspring around to rely on - working 
in other places as migrant workers of offspring is more important than the function of taking care of parents. The transfer of labor from rural areas to urban areas is an inevitable phenomenon in social development process. Also, the scope and pace of labor immigration will increase with the development of society. For the less developed rural areas, social elderly support measures are very imperfect due to restricted social and economic development. Family support for the elderly is a feasible manner for present time. Labor immigration is bound to have an impact on elderly support willingness of rural households. At the same time, with the influence of decline in fertility and elderly mortality, life expectancy of the elderly population is also extended. From the perspective of socio-economic conditions, it is difficult to universally implement the policy of preferential and favorable treatment in the rural elderly population; under the influence of foreign culture, some traditional cultures are changing. The position occupied by the elderly and won by virtue of grasp of experience in economic production activities has ceased to exist. The provisions with respect to respect for the elderly of traditional custom and religious doctrine are often ignored or forgotten. Social consensuses collapse gradually and interpersonal solidarity gradually becomes indifferent in the society tending to be more and more individualized. As a result, despite the expansion of individual freedom, the ability or autonomy to honor such freedom declines, which is the paradox of individualization. However, the concept and practice base that the elderly rely on their family have not changed. Also, the order of the Chinese native soil society for thousands of years in China has not changed. "The factor of individual characteristics of rural residents exerts small impact on their residence willingness regarding elderly support. The factor of family characteristics and sources for economic support by contrast have the most significant influence, which means that elderly support choice of the rural population is closely related to distribution of family resources" (Hu Ying, Yang Kang, \& Shu Tai, 2014).

\section{ORDER RETURN: DUAL RESPONSIBILITY OF STATE AND INDIVIDUALS}

For the Chinese native soil society, culture is tradition. Governing by ritual is the compliance of the Chinese native soil society with traditional rules. The development of Chinese civilization for thousands of years is accumulated based on production in agricultural society. The reaction in the Chinese native soil society is the acquaintance society featuring measurement or inferring of others from own perspectives. It follows the experience accumulation based on the patriarchal and elders system and responds to the impact of foreign cultural elements. Meanwhile, based on the principle of "the possibility of governing by ritual must be under the premise that traditions can be used to deal with life issues effectively" (Fei Xiaotong, 2005), it maintains the social order of differential pattern. Any culture maintains certain social order. This order reflects not only the relationship between human and nature, but also the relationship between people. With respect to the form of performance, the legal order of the Chinese native soil society as etiquette and customs have unwritten and non- systematic features; with respect to effectiveness sources, the order of etiquette and customs mainly roots in the authority of patriarchal clans and patriarchal clan systems, rather than compelling force of the state; with respect to implementation ways, the order of etiquette and customs does not rely on the order of national judicial practice, but cultivation of elderly authority in enlightenment to maintain order running. China's vast rural areas have not been divorced from rustic features. Their fundamental value criteria still exist without transcending the human relations of such difference sequence. Family is still the most basic community organization in the Chinese native soil society. Filial piety and fraternal duty become an ethical order for family establishment and a starting point for a family to integrate into the village and society. Thus, filial piety becomes the foundation and main element of the order of governing by ritual in the Chinese native soil society. Filial piety is also educated by parents to their offspring in order to ensure the operation of the order of governing by ritual. In addition, the "although enlightened power is most evident in the parentchild relationship, it is not limited to parent-child relationship. All cultural and non-political coercion includes such power" (Fei Xiaotong, 2005). Filial piety culture inherited by Chinese people has become an internalized habit, derived from respect for parents to respect for the elderly, care for offspring, care and assistance among brothers and friendly exchanges with the neighborhood. An issue of a family is a matter of the "whole village". The fundamental of living on the land and the social basis of filial piety culture have not changed. We should attach importance to this social order of internality and should recognize and advocate the culture of filial piety in the Chinese native soil society to help it remain the healthy development state. The country is precisely the "intermediary agent connecting and communicating modernity and local knowledge of villages" $(\mathrm{Wu} \mathrm{Yi}, 2002)$. Individuals are divorced from the control of local knowledge in modern development. Tradition maintenance and personal enlightenment are the responsibility of the state.

"Elderly support as a family function is also changing, that is, part of the functions undertaken by the family is gradually separated from the family inside out" (Chong Yongsheng, Li Zengsen, 2006). This change is an inevitable trend in rural areas. Wealth target submits to arrangements of economic development. Family is increasingly reflected as the carrier of economic development, ruining the function of family as an intermediary between individual and society. The root of changes in family size and function in rural areas lies in the society's pursuit of modernity. "There are actually three kinds of modernity currently challenging China and promoting the development of China: First, modernity with capital as the core; second, modernity with labor as the core; third, modernity with people's free and comprehensive development as the core (Jiang Yihua, 2008)". The most direct expression in the countryside of China's modernity pursuit on the micro level: on one hand, population movements arising from migration to work increase the income of rural people and improve their lives. Interactions between capital and labor affect the order of elderly support in rural areas; on the other hand, population movements 
arising from migration to work lead to changes in the status of family members in rural areas, affecting the arrangements of traditional life of the Chinese native soil society. Interactions between capital and personal development affect the order of elderly support in rural areas.

About the elderly support issue, we should attach importance to the role of traditional culture of filial piety and analyze composition and degree of the traditional culture of filial piety in the Chinese native soil society, which is a way to solve the difficulties of elderly support in rural China arising from pursuit of modernity. Therefore, establishment of modern culture of elderly support and re-promotion of filial piety have become the countermeasures raised by many scholars on the issue regarding rural elderly support. "Maintaining and promoting family support in a period of time and at the same time developing home care model can make time and provide support for maturity of the social elderly support system, which conforms to realistic needs" (Yang Qingzhe, 2013). This return to the tradition, in a way, is the result arising from people's pursuit of modernity at present. "The nature of modernity is a kind of posttraditional order, but under this order, traditions and customs as a guarantee of order have not been replaced by the inevitability of rational knowledge" (Giddens, 1998). Rural elderly, in terms of physical and psychological aspect, or economic and social perspective, are the benefit-lost group mostly affected in the pursuit of modern development. Rural elderly make a living with high-labor intensity when they were young. As a result, the chances of suffering from various diseases increase significantly with age. Chronic diseases become the biggest problem troubling them. Plus psychological interference from negative emotions such as loss and loneliness, dual physical and mental torture make one day of the elderly seem like a year under the circumstance of limited income and offspring away from them.

With regard to the elderly support issue from a national perspective, establishment of a universal-type system for elderly support is the guiding ideology for the government to respond to the rapidly aging society. Such system "is based on social insurance, social relief and social welfare, focuses on basic elderly support, basic medical care and system of subsistence allowances, and supplements with charity and commercial insurance" However, only parts of the country's urban population, migrant workers in some cities and a small amount of rural population have joined the rural old-age insurance. Elderly support of the vast majority of the rural population still relies on land accumulation and offspring's support. The ideological understanding of "rely on support from offspring when getting old" still existing in people's mind nowadays is limited by traditional concept and economic conditions. The combination of the culture of filial piety and "having sons for elderly support" in the absence of the national welfare system can achieve both emotionalsense elderly support, and elderly support with material support, which is the most effective life support that the rural elderly can acquire with the lowest cost. Rural elderly hope to have fixed "retirement" wages as urban people, even a few dozen yuan a month, because they are really unable to afford medical expenses relying on income from farming.

\section{CONCLUSION}

Therefore, with respect to the current issue of rural elderly support encountered, medical treatment welfare is the area that we are able to spare no effort to effectively solve, which is also an effective path for the country to enlighten people for order return. Meanwhile, the state should greatly increase investment in rural health care construction, improve the level of medical care, improve medical service, increase efforts to train barefoot doctors and health workers, form good medical environment, combine appropriately urban medical institutions and rural health centers, enable villagers to receive medical treatment locally and timely for minor illnesses, and receive referral treatment for further medical treatment for serious illnesses timely. In addition, the state should open up urban and rural old-age insurance, subsistence allowances, urban medical insurance and new rural cooperative medical system, and establish and improve the rural medical aid and living assistance system for poor rural elderly, in order to enable the rural elderly to receive elderly support once getting old and medical services once getting ill as soon as possible, and to ensure that the rural elderly can enjoy their rights matching their contributions to the country.

\section{REFERENCES}

[1] Anthony Giddens. (1998). Modernity and self identity - self and society in late modern times. Shanghai: SDX Joint Publishing Company.

[2] Cao Liqian, \&Gao Shanxiu. (2008). A study on the thoughts of filial piety and provison for the aged in traditional Chinese culture. Journal of Shandong Normal University(Humanities and Social Sciences), 220, 88-91.

[3] Chen Fang. (2014). A model change of the elderly supporting in the underdeveloped rural areas: From family-support to economic selfsufficiency. Population and Society, 116, 76-80.

[4] Fei Xiaotong. (2005). Chinese native soil society. Beijing: Beijing Publishing House.

[5] He Xuefeng. (2009). Rural intergenerational relations theory: The value basis of intergenerational relations. Social Science Research, 184, 84-92.

[6] Hu Ying, Yang Kang, \&Shu Tai. (2014). Empirical study of selection of residence willingness for elderly support of rural residents. The World of Survey and Research, 251, 24-29.

[7] Jiang Yihua. (2008). Modernity: About China. Beijing: Beijing Normal University Press.

[8] Pan Guangdan. (1994). Collected Works of Pan Guangdan (Vol.1). Beijing: Peking University Press.

[9] Song Siyun. (2010). Social order on the harmony perspective. Theoretical Exploration, 183, 31-34.

[10] Su Baozhong. (2009). Research on Elder Support Issues in Rural China. Beijing: Tsinghua University Press.

[11] Tang Chan, Ma Chunhua, \&Shi Jinqun. (2008). Resources crisis of elderly support modes of rural families. Chinese Cadres Tribune, 239, $39-41$.

[12] Wu Yi . (2002). Authority and Order under the Change of Village Governing - Expression of Dongshuang Village in Sichuan in the 20th Century. Beijing: China Social Sciences Press. 
[13] Yang Qingzhe. (2013): Cultural perspectives for solving the problems of rural elderly support: To break the rural elderly support dilemma with the culture of filial piety. Scientific Socialism, 151, 105-107.

[14] Zhang Desheng. (2008). Confucian Ethics and Order Complex Sociological Interpretation. Shanghai: Shanghai People's Publishing House.

[15] Zhong Yongsheng, \&Li Zengsen. (2006). Evolution of traditional family elderly support in China: Change results of cultural and ethical idea. Population Journal, 166, 51-55.

[16] Lowry, Deborah Sue Wilson. (2008). Relative expectations in rural China: Later-life distinction, duty, dreams, and discontent. A Dissertation, Submitted to Michigan State University, in partial fulfillment of the requirements for the degree of the PH.D, Department of Sociology.

[17] Rita Jing-ann Chou. (2010). Willingness to live in eldercare institutions among older adults in urban and rural China: A nationwide study. Journal of Ageing and Society, 30, 583-608. doi: 10.1017/S0144686X09990596

[18] Thomas J. Durant, Jr., \& Ollie G. Christian. (2006). Caregiving to aging parents. Forumon Public Policy, 2006, Retrieved from http://forumonpublicpolicy.com/archive07/durant.pdf. 